\author{
Alexandre Demoule \\ Jordi Rello
}

\section{High flow oxygen cannula: the other side of the moon}

Received: 23 April 2015

Accepted: 29 April 2015

Published online: 3 June 2015

(C) Springer-Verlag Berlin Heidelberg and ESICM 2015

\section{A. Demoule}

Neurophysiologie Respiratoire Expérimentale et Clinique, Sorbonne Universités, UPMC Univ Paris 06, and INSERM, UMR_S 1158, 75005 Paris, France

\author{
A. Demoule $(\bowtie)$ \\ Service de Pneumologie et Réanimation Médicale (Département \\ "R3S"), Groupe Hospitalier Pitié-Salpêtrière Charles Foix, AP-HP, \\ Paris, France \\ e-mail: alexandre.demoule@psl.aphp.fr \\ Tel.: 33142167761
}

J. Rello

Vall d'Hebron Institute of Research (VHIR), CIBERES, Barcelona, Spain

J. Rello

Critical Care Department, Hospital Vall d'Hebron, Barcelona, Spain

J. Rello

Universitat Autonoma de Barcelona, Barcelona, Spain

High flow nasal cannula (HFNC) is a high-flow oxygen system that can deliver up to $100 \%$ heated and humidified oxygen via a wide-bore nasal cannula at a maximum flow of $60 \mathrm{l} / \mathrm{min}$. HFNC was first introduced to prevent atelectasis and apneas in premature babies. Most of the studies in the pediatric literature suggest use in management of children younger than 24 months of age with moderately severe acute viral bronchiolitis, in whom HFNC may reduce the need for invasive respiratory support, thus potentially lowering costs with clinical advantages and minimal adverse events [1].

More recently, there has been a growing interest in the use of HFNC in adults. In the setting of acute respiratory failure, HFNC may allow the delivery of oxygen supplementation to patients with severe hypoxemia in whom maintaining an appropriate tissue oxygenation requires a high inspiratory flow of oxygen. In addition, HFNC generates positive end expiratory pressure, flushes dead space, and increase end expiratory lung volume [2].

In patients with acute hypoxemic respiratory failure, HFNC reduces respiratory rate and improves dyspnea and oxygenation [3]. Moreover, preliminary results of a recent randomized controlled trial show that HFNC provided to severe respiratory failure patients might reduce ICU mortality [4]. As a consequence of these encouraging data, potential indications of HFNC have spread and the potential benefit of HFNC has been studied in settings other that acute hypoxemic respiratory failure (Table 1). A recent before-after monocentric study suggested that keeping HFNC during an endotracheal intubation (ETI) procedure could improve pre-oxygenation and reduce severe hypoxemia [5, 6]. Nasal prongs left in place after rapid sequence intubation during laryngoscopy could indeed achieve apneic oxygenation and reduce desaturation during rapid sequence ETI. Also recently, a randomized controlled trail has shown that HFNC delivered in the post-extubation setting improves comfort and oxygenation and reduces the rate of reintubation [7]. A wind of enthusiasm was blowing. The three studies published in this issue of Intensive Care Medicine are in contrast with all these univocally positive data and should at least temper our enthusiasm. They should overall help to remind us that a given treatment may not suit every patient and that we should give the right treatment to the right patient.

The retrospective study by Kang et al. [8] enrolled all patients who received HFNC therapy that eventually failed and who were subsequently intubated. Patients were 
Table 1 Recommended use of high flow nasal cannula (HFNC) in clinical practice

There is some evidence for a benefit

There is no evidence for a benefit

There is some rationale against the use in clinical practice

The benefit remains to be investigated
Children younger than 24 months of age with viral bronchiolitis

Palliative care

Acute hypoxemic respiratory failure with rapid improvement

Pre-oxygenation before rapid sequence intubation of non-hypoxemic patients Acute cardiogenic pulmonary edema

Extubation of patients after pneumonia or trauma

Sleep-related hypoventilation in chronic obstructive pulmonary disease

Acute asthma in children

Extubation of obese patients after cardiac surgery

Pre-oxygenation before rapid sequence intubation of hypoxemic patients Flexible bronchoscopy

Acute hypoxemic respiratory failure associated with any other organ failure Acute hypoxemic respiratory failure with late intubation

Bridge to lung transplant

Acute hypoxemic respiratory failure in immunocompromised patients

Pre- or inter-hospital transport

Acute exacerbation of chronic obstructive pulmonary disease classified according to whether failure occurred early (within $48 \mathrm{~h}$ ) or late (at least $48 \mathrm{~h}$ ) after the initiation of HFNC. The authors observed that failure of HFNC late (at least $48 \mathrm{~h}$ ) after its initiation was associated with significantly higher overall ICU mortality, poorer extubation success, and fewer ventilator-free days. In propensity-adjusted and -matched analysis, early intubation was associated with better overall ICU mortality. These results fit with a recent cohort study of patients with severe acute respiratory failure in which after only $6 \mathrm{~h}$ of HFNC, nonresponders had significantly worse hypoxemia and increased oxygen requirements, suggesting objective exclusion criteria and that the decision to intubate can be anticipated within $6 \mathrm{~h}$ of an HFNC trial [9]. These results also remind us of the reports on non-invasive mechanical ventilation (NIV) that showed many years ago that NIV failure could be strongly associated with higher mortality in such patients [10], inasmuch as NIV failure occurred late [11]. However, the study by Kang et al. [8] does not tell us that HFNC should not be used in acute hypoxemic acute respiratory failure. Nevertheless, it suggests that HFNC should be stopped early in patients who are at high risk of intubation. Definitely, this study calls for larger ones that could provide reliable predictors of HFNC failure.

The prospective multicenter randomized controlled study by Vourc'h et al. [12] evaluated the efficiency of HFNC for pre-oxygenation compared to high fraction inspired oxygen facial mask in severely hypoxemic adults requiring intubation. HFNC was unable to prevent desaturation but provided similar lowest saturation levels to those achieved with oxygen facial mask. Using HFNC without discontinuation during an apneic period was thus not more effective in preventing desaturation, regardless of the severity of respiratory distress. These results are in contradiction with the single-center trial, before-after design by Miguel-Montanes et al. [5]. However, this latter trial included patients regardless of the reasons for intubation. In many patients, respiratory failure was not the main issue. In addition, patients were less severely hypoxemic. This may explain the difference between the results of these two trials. It is noteworthy that none of these two trials compared HFNC to NIV, which prevents efficiently profound desaturation during intubation in severely hypoxemic patients [13]. Once again, this study does not tell us that HFNC should not been used to secure intubation. However, it suggests that further works should aim at defining the subgroups of patients in which HFNC could be beneficial and identifying the respective roles and potential benefit of NIV and HFNC for pre-oxygenation during rapid sequence ETI.

Finally, the randomized controlled single-centre trial study by Corley et al. [14] compared HFNC to standard oxygen therapy in recently extubated obese patients (body mass index at least $30 \mathrm{~kg} / \mathrm{m}^{2}$ ) following cardiac surgery. The study showed that compared to standard oxygen therapy, HFNC did not improve atelectasis, oxygenation, respiratory rate, or dyspnea, nor did it reduce rates of failure of allocated therapy. Although these results are in accordance with previous ones [15], they are in contradiction with the recent study by Maggiore et al. that showed that HFNC improved oxygenation, comfort, and reintubation rate in the post-extubation setting [7]. However, this study was conducted in patients with acute respiratory failure from pneumonia and trauma, which are quite different from obese patients extubated right after cardiac surgery. The study by Corley et al. does not tell us that HFNC is not beneficial in the post-extubation setting. However, it suggests that HFNC should be of benefit to some selected patients rather than to all patients.

In conclusion, there is no therapy that is efficient in every patient and in every type of acute respiratory failure, with no safety concerns. The three studies published in this issue of Intensive Care Medicine show us that we should improve our knowledge regarding the right indications for HFNC (Table 1). More randomized studies are therefore needed to identify adequate candidates. Like in 
other approaches in critical care, criteria for HFNC initiation and failure should be personalized.

Conflicts of interest Alexandre Demoule has research contracts with Maquet SA, Covidien, and Philips. He has received lecture fees from Covidien and Maquet. Jordi Rello does not have conflicts of interest.

\section{References}

1. Beggs S, Wong ZH, Kaul S, Ogden KJ, Walters JA (2014) High-flow nasal cannula therapy for infants with bronchiolitis. Cochrane Database Syst Rev 1:CD009609

2. Spoletini G, Alotaibi M, Blasi F, Hill NS (2015) Heated humidified high-flow nasal oxygen in adults: mechanisms of action and clinical implications. Chest. doi:10.1378/chest.14-2871

3. Lenglet H, Sztrymf B, Leroy C, Brun P, Dreyfuss D, Ricard JD (2012) Humidified high flow nasal oxygen during respiratory failure in the emergency department: feasibility and efficacy. Respir Care 57:1873-1878

4. Frat JP, Groupe FLORALI, the REVA network (2015) Essai FLORALI: comparaison entre l'oxygénation standard, l'oxygénothérapie nasale à haut débit et l'association ventilation non invasive/oxygénothérapie nasale à haut débit. Reanimation 24:S2

5. Miguel-Montanes R, Hajage D, Messika J, Bertrand F, Gaudry S, Rafat C, Labbe V, Dufour N, Jean-Baptiste S, Bedet A, Dreyfuss D, Ricard JD (2015) Use of high-flow nasal cannula oxygen therapy to prevent desaturation during tracheal intubation of intensive care patients with mild-to-moderate hypoxemia. Crit Care Med 43:574-583
6. Sztrymf B, Messika J, Bertrand F, Hurel D, Leon R, Dreyfuss D, Ricard JD (2011) Beneficial effects of humidified high flow nasal oxygen in critical care patients: a prospective pilot study. Intensive Care Med 37:1780-1786

7. Maggiore SM, Idone FA, Vaschetto R, Festa R, Cataldo A, Antonicelli F, Montini L, De Gaetano A, Navalesi P, Antonelli M (2014) Nasal high-flow versus Venturi mask oxygen therapy after extubation. Effects on oxygenation, comfort, and clinical outcome. Am J Respir Crit Care Med 190:282-288

8. Kang BJ, Koh Y, Lim CM, Huh JW, Baek S, Han M, Seo HS, Suh HJ, Seo GJ, Kim EY, Hong SB (2015) Failure of high-flow nasal cannula therapy may delay intubation and increase mortality. Intensive Care Med 41:623-632

9. Rello J, Perez M, Roca O, Poulakou G, Souto J, Laborda C, Balcells J, Serra J, Masclans JR (2012) High-flow nasal therapy in adults with severe acute respiratory infection: a cohort study in patients with 2009 influenza A/H1N1v. J Crit Care 27:434-439

10. Demoule A, Girou E, Richard JC, Taille S, Brochard L (2006) Benefits and risks of success or failure of noninvasive ventilation. Intensive Care Med 32:1756-1765
11. Moretti M, Cilione C, Tampieri A, Fracchia C, Marchioni A, Nava S (2000) Incidence and causes of noninvasive mechanical ventilation failure after initial success. Thorax 55:819-825

12. Vourc'h M, Asfar P, Volteau C, Bachoumas K, Clavieras N, Egreteau PY, Asehnoune K, Mercat A, Reignier J, Jaber S, Prat G, Roquilly A, Brule N, Villers D, Bretonniere C, Guitton C (2015) High-flow nasal cannula oxygen during endotracheal intubation in hypoxemic patients: a randomized controlled clinical trial. Intensive Care Med

13. Baillard C, Fosse JP, Sebbane M, Chanques G, Vincent F, Courouble P, Cohen Y, Eledjam JJ, Adnet F, Jaber S (2006) Noninvasive ventilation improves preoxygenation before intubation of hypoxic patients. Am J Respir Crit Care Med 174:171-177

14. Corley A, Bull T, Spooner AJ, Barnett AG, Fraser JF (2015) Direct extubation onto high-flow nasal cannulae postcardiac surgery versus standard treatment in patients with a $\mathrm{BMI} \geq 30$ : a randomised controlled trial. Intensive Care Med 41:887-894

15. Parke RL, McGuinness SP, Eccleston ML (2011) A preliminary randomized controlled trial to assess effectiveness of nasal high-flow oxygen in intensive care patients. Respir Care 56:265-270 